\title{
Factors Affecting Performance of Excavating Equipment: An Overview
}

\author{
Dushyant A. Deshmukh ${ }^{1}$, Parag S. Mahatme ${ }^{2}$ \\ ${ }^{1}$ PG Student, Department of Civil Engineering, Prof. Ram Meghe College of Engineering and Management, Badnera \\ ${ }^{2}$ Assistant Professor, Department of Civil Engineering, Prof. Ram Meghe College of Engineering and Management, Badnera
}

\begin{abstract}
Construction industry is one of the highly increasing industries in the world. The extent of construction in India has increased up to high level these days. Every construction work starts with earthmoving operations during its initial phase. Heavy construction equipment is routinely used in construction project that entail earthmoving operations. The utilization of excavating equipments reduces the reliance of the construction industry on intensive labor to a certain extent and generally increases construction productivity. The improper selection and use of excavator can cause excessive costs, time and injuries to labors. Time required for excavation work depends on the performance of equipment. There are various factors that can affect excavator's performance and productivity. In this paper, we have studied literature and identified some of those factors. It is found that, understanding fundamentals of such factors is important role of construction manager for better excavating equipment performance.
\end{abstract}

Keywords: Construction Equipment, Excavating Equipment, Excavator's Productivity, Performance Factors.

\section{Introduction}

The development of infrastructure is one of the important aspects for overall development of the country. The rapid development of the construction industry in recent years and the magnitude of the present-day constructions involved the movement of large amount of earth excavations, cuttings and embankments may be a substantial part of the overall project. These operations are relatively repetitive and machineoriented, being performed under the pressure to improve productivity, efficiency and safety.

Construction equipment have assumed role of great importance to Engineer in the modern construction industry. The use of equipment for accomplishing construction task is increasing rapidly. It is found that in a building project, the equipment cost may vary from $5 \%$ to $10 \%$ of the direct cost. While in highway construction project, it may reach up to $40 \%$ of the project direct cost. Thus, understanding the fundamentals of equipment evolves great importance for the contractors as well as engineers in the field (Nilesh Ayane et al. 2015)[8].

As the problems of management become more complex, the divergence of results as obtained through conventional procedures and actual results becomes greater. To achieve the success of the project within cost and time will require adequate planning and implementation of earthworks and earthwork activities.

\section{Objective}

Equipment selections a critical factor when trying to complete a project within budget and on schedule. Without the proper working equipment, productivity decreases, delays increase, possible injuries occur and unnecessary costs incurred. It is important for all the partied involved in an earth-moving operation that the project begins with the most appropriate selection of the equipment needed to perform the work. Proper selection of equipment contributes to project efficiency and to increased profits (Mohammed Faiz, 2013)[6].

There are varieties of factors that a good manager should consider in acquiring the equipment. A good construction manager should identify these factors and by evaluating them decision making is possible.

\section{Literature Review}

Various literatures are studied to find some of the common factors that can affect the performance of excavator on construction site.

Masoud Navazandeh Sajoudi et al. (2011)[5] focused on the factors which affects on Construction Equipment Acquiring (CEA) ways. Purchasing with cash, financing through a loan, renting and leasing are four most common ways for CEA. For having the best result in profit for a construction industry, choosing the best alternative for obtaining equipment is one of the most important issues. The best equipment selection strategy depends on accurate estimates of revenues and cost and also some non-financial factors that affect on choosing acquisition mode. The purpose of this study is to evaluate these factors, to find out which factor is more important and which one has the lowest effect on acquisition mode. For this purpose, the factors that effect on CEA has been identified in a wide research with the help of literatures and by interviewing from experts in construction. For evaluation of such factors, the author prepared questionnaires using information and distributed it between construction professionals. One sample t-test has been carried out in this study as a statistical method. Author looked at what information would be most important for the contractors and project manager in finding best alternative for CEA methods and concluded that the contractors should consider both financial and non-financial factor to make a good decision. The degree of importance for each factor has been specify by experts and experienced construction managers. 


\section{International Journal of Science and Research (IJSR) \\ ISSN (Online): 2319-7064 \\ Index Copernicus Value (2013): 6.14 | Impact Factor (2014): 5.611}

In generally, it is required to excavate the ground by the construction machine such as the hydraulic excavator at the construction sites. In recent years, some unmanned operation systems for the hydraulic excavator are required and some systems are already developed. However, it is difficult to realize effective operation utilizing such systems, because the operator cannot sense ground condition. The skillful operator adaptive their operation to the excavating environment based on the experience, and realizing the efficient excavating. In this study, Yuki Sakaida and Daisuke Chugo, (2006)[4] described the experiment for extracting operator's skill for controlling unmanned hydraulic excavator. They compared the operation of skillful with nonskillful operator and discuss the result for the modeling of operator's skill. This comparison is carried out on the basis of interview of the operator and observing his way of work and handling of equipment. They interviewed a skillful operator to know the reason of his efficient works and obtained the qualitative answers that, the operator acquired the skill from the empirical knowledge by the operation work for many years. However, it is not a quantitative answer of what the factors are connect for efficient work. On the basis of observation and comparison they found that the accuracy of the skillful operator is more than that of non-skillful operator. From these results, they have revealed that skillful operator realizes unified trajectories of the bucket with quick moving and this causes the efficient performance.

Nilesh D. Chinchore et al. (2014)[3] Construction equipment planning and selection plays crucial role for the success of construction firms. Equipment saves manpower, which is becoming costly and more demanding day by day. Inadequate manual processes of equipment planning and selection and the subjective decisions of equipment managers usually result in major losses in terms of cost and time. This study aims at identifying construction equipment for executing project tasks, assessing equipment performance capability, forecasting date wise requirement of number and type of equipment and finally participating in the selection of equipment to be acquired. Although, in this work, author suggested sourcing information and some common factors affecting selection of equipment such as scope of work, productivity of equipment, suitability for job condition, size of equipment, uniformity in type, use of standard equipment, unit cost of production, technical consideration etc. Considering these factors author concluded that, proper selection and planning of equipment is very important for timely completion of project, within plant cost and for increasing profit, margin. Selection is a process in which the equipment that is most suitable for a particular job is found out and thus selection and planning needs to exercise very seriously as it is one of the factors that affect the progress of work.

Mr. Nilesh Ayane et al. (2015)[3] In construction operations on a large scale require the standard Equipments for Effective operations especially in the area of infrastructural development. This work reviews the goals and benefits of implementing Total Productive Maintenance (TPM) and it also focuses on calculating the Overall Equipment Effectiveness (OEE) in construction equipments. OEE is described as one performance-measurement tool to materialize the quest for perfection of lean manufacturing into daily practices. The objective of TPM is to achieve zero breakdowns and zero defects related to equipment, which could lead to improvements in the production rate, reduction in inventory, reduction in costs and eventually increases in labor productivity. The author carried out this study within major construction companies in India. He has visited some companies in local government within country and found that most of the companies use equipment in their infrastructure projects. On the basis of visit and observation of execution, he gathered the data related to the equipment used in road construction project and calculated Overall Equipment Effectiveness which results in Total Productive maintenance which leads to both short and long-term improvements. Through this review author concluded that, the Total productive maintenance (TPM) methodology is a proven approach to increase overall equipment effectiveness (OEE) of equipment.

Mohammed Faiz (2013)[6] In this study, the author studied operation of the hydraulic excavator from the data obtained by monitoring the machine during regular operation period. The objective of the work is to build an understanding of how machine usage affects performance, extending across productivity and to provide an analytical approach for identifying causes of productivity loss, evaluating their performance and to understand how the machine is used and how different method of use relates to its productivity and reliability. This study was conducted at 12 different job sites consisting different hydraulic hoe excavator. The actual job operating condition which might affect productivity were identified and recorded which includes causes of material, operator's skill, condition of hoe, haul unit exchange, sie of hauling unit, height of cut etc. The time-motion study was conducted and productivity, total cycle time and cycle time of element were estimated for each equipment with respect to bucket size. The estimations were made following the guidelines given in the manufacturer's performance handbook. The actual productivity was then calculated based on the data obtained from site. The term Production Performance Ratio (PPR) was used to compare the actual productivity against estimated productivity to demonstrate the amount of loss of productivity. This Production Performance Ratio was found to be less than 1 which indicated that, the equipment failed to perform as per it was expected to be. It is cleared by the author that, all seconds saved per cycle meant nothing if the hydraulic excavator did not have trained operator.

\section{Factors Affecting Performance of Excavators}

Based on the literature and related work, following are some factors found that affecting on performance of excavator,

\subsection{Proper Equipment Selection}

Equipment is a critical factor in construction project. Rational selection of suitable equipment leads to profit for contractors. At the same time, miscalculation proper size and number of required equipment for the project may result in suffering from overhead costs and wastage of time. Therefore, contractor considers proper selection of earthmoving equipment a vital factor for any construction 


\section{International Journal of Science and Research (IJSR) \\ ISSN (Online): 2319-7064}

Index Copernicus Value (2013): 6.14 | Impact Factor (2014): 5.611

project (Remon F. Aziz and Yasser R. Aboel-Magd, 2015)[2].

\subsection{Site Condition}

The performance of excavator depends on site conditions also which includes the physical conditions of site such as topography and geology of the site, geotechnical characteristics of ground or rocks etc. Excavation might be tough for site containing hard soil. Rate of excavation may vary with respect to climatic changes also like temperature, rain snow etc.

\subsection{Cycle Time}

Cycle time is defined as the amount of time taken by machine to perform a repetitive segment of an operation, typically measured as the time it takes the machine to return to the same position. It is the time taken to complete one entire excavating process of an excavator which includes excavation time, time to swing to dumping position, dumping time and time to return to the digging position (Vishnu Lal M., 2013)[7].

\subsection{Bucket Size}

A bucket is a bulk material handling equipment provided at the end of the arm of an excavating machine. Selection of bucket size depends on the material to be excavated. The size of this bucket determines its capacity to excavate the material in one particular cycle. Thus, maximum capacity of bucket can save number of cycle and time required for excavation.

\subsection{Angle of Swing}

Angle of swing is a horizontal angle in between the position of excavator while excavating and the hauling unit where it dumps the material. Is is one of the element of cycle time. If the angle of swing is more, the cycle time required will be more and vice-versa. Thus, keeping the angle of swing minimum can save the cycle time of excavator.

\subsection{Repairs and Maintenance of Equipment}

When it comes to construction equipment, regular maintenance is one of the most important factors in terms of cost and performance. Good maintenance will minimize maintenance and repair costs and maximize production and profits, with greatest impact on profit. It helps to control costs and service intervals, lengthens equipment life, minimizes downtime and adds resale value.

\subsection{Operator's Skill}

An operator plays a major role in working of any equipment. Proper use of equipment is what we need to obtain best result from the machine. A skilled or trained operator can handle the equipment in an effective manner providing maximum output from machine. Improper use equipment can cause damages to it and injuries to the operator as well. Thus, operator's skill is an important parameter to be considered.

\section{Results and Conclusion}

In this rapidly increasing construction sector, equipments plays an important role in completing construction activities. Now-a-days, due to labor, cost and time problems, the use of equipment has gained significant importance. Thus, it is essential to understand it's fundamentals towards success of project.

In this paper, we have studied different literatures related to excavators in terms of its planning, selection and performance. Some of the common factors that can affect the performance of excavating equipment has been identified and discussed in this work and on the basis of this, we can conclude following points,

1) Incorrect equipment selection may directly affect to its productivity for that particular work.

2) Excavation is generally faster for soft soil as compared to hard strata.

3) Greater angle of swing results in greater cycle time which may lead the work to delay.

4) Time saved per cycle is nothing if the operator's skill is poor.

5) Regular repairs and maintenance of equipment may increase its life providing better performance.

Thus, it is important role of construction manager to understand and properly utilize such factors for better performance of excavating equipments.

\section{References}

[1] Miquel Casals, Nuria Forcada, Xavier Roca, "A Methodology To Select Construction Equipment," Polytechnic University of Catalonia, Department of Construction Engineering, C/Colom 11, Edifici TR-5, $08221 \quad$ Terrassa, Barcelona, Spain, miquel.casals@upc.es.

[2] Remon F. Aziz, Yasser R. Aboel-Magd, "Suitably Selection for Earthwork Equipment In Egyptian Sites," International Journal of Education and Research Vol. 3 No. 1 January 2015.

[3] Mr. Nilesh D. Chinchore, Prof. Pranay R. Khare, "Planning and Selection of Heavy Construction Equipment in Civil Engineering," International Journal of Engineering Research and Applications, ISSN: 22489622, Vol. 4, Issue 12( Part 1), December 2014, pp.2931.

[4] Yuki Sakaida, Daisuke Chugo, Kuniaki Kawabata / Hayato Kaetsu, Hajime Asama, "The Analysis of Excavator Operation by Skillful Operator," ISARC2006.

[5] Masoud Navazandeh Sajoudi, Mohammadali Kazerooni Sadi, Arham Abdullah, Mohammadreza Kasraei, Hoda Rezaie, "Evaluation of Factors Affecting on Construction Equipment Acquisition Methods in Malaysia," 2011 International Conference on Information and Finance IPEDR vol.21, 2011.

[6] Mohammed Faiz, "Comparative Study of Productivity and Cycle Times of Different Excavators With Respect To Bucket Size," Visvesvaraya National Institute of Technology, Nagpur, 2013.

[7] Vishnu Lal M., "Development of Consolidated Charts for Estimation of Excavator Productivity," Visvesvaraya National Institute of Technology, Nagpur, 2012-13. 


\section{International Journal of Science and Research (IJSR) \\ ISSN (Online): 2319-7064}

Index Copernicus Value (2013): 6.14 | Impact Factor (2014): 5.611

[8] Mr. Nilesh Ayane, Mr. Mangesh Gudadhe "Review Study on Improvement of Overall Equipment Effectiveness in Construction Equipments," IJEDR, Volume 3, Issue 2, ISSN: 2321-9939, 2015. 